\title{
NONRADIATION-INDUCED THERMOLUMINESCENCE
}

by

Charles R. Rhyner and John R. Cameron

Department of Physics University of Wisconsin Madison, Wisconsin

\section{INTRODUCTION}

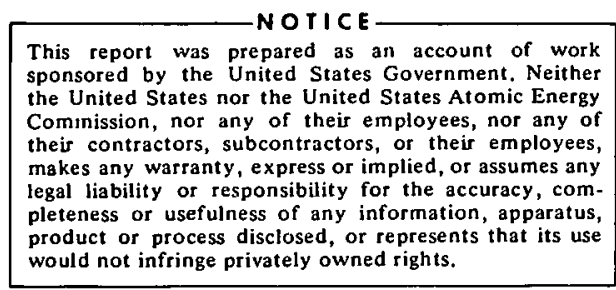

The nonradiation-induced thermoluminescence (NRI-TL) of LiF powder was studied. Two different types of powder were studied: one was relatively pure optical grade scrap, obtained from the Harshaw Chemical Company in August, 1963 (H63A); the second material was TLD-100 LiF obtained from the same company. The methods of producing the various peaks of the glow curve or combinations of the peaks were studied. The observed peaks were classified as R (radiationInduced), $T$ (Tribo- or mechanically-induced), S (shaking or perhaps charge-induced), and D (duration-induced, perhaps caused by absorbed gases). The principal difficulty in performing this study was the nonreproducibility of the magnitudes of all but the $R$ peak; for this reason the results stated are, in general, qualitative rather than quantitative.

\section{NRI-TL GLOW CURVES}

The glow curves of $\mathrm{H} 63 \mathrm{~A}$ and $\mathrm{TLD}-100$ differ principally $\therefore$ In the location of the R-Peak. In H63A this peak occurs at about $110^{\circ} \mathrm{C}$, whêreas in TLD-100 the R-peak occurs at about $200^{\circ}$. C. In the early work reproducibility of the NRI-TL peaks was very poor. It was improvod by óbtàining a more uniform crystal size. The reproducibility of the $s$-peak was best with powder of 120-180 mesth (Tyler). The standard deviation of the area of the S-peak was about $6-8 \%$. The finer mesh 


\section{DISCLAIMER}

This report was prepared as an account of work sponsored by an agency of the United States Government. Neither the United States Government nor any agency Thereof, nor any of their employees, makes any warranty, express or implied, or assumes any legal liability or responsibility for the accuracy, completeness, or usefulness of any information, apparatus, product, or process disclosed, or represents that its use would not infringe privately owned rights. Reference herein to any specific commercial product, process, or service by trade name, trademark, manufacturer, or otherwise does not necessarily constitute or imply its endorsement, recommendation, or favoring by the United States Government or any agency thereof. The views and opinions of authors expressed herein do not necessarily state or reflect those of the United States Government or any agency thereof. 


\section{DISCLAIMER}

Portions of this document may be illegible in electronic image products. Images are produced from the best available original document. 
powder (180-200) gave approximately twice the size S-peak but was less reproducible. The general form of the glow curves is shown in Fig. 1 and 2 .

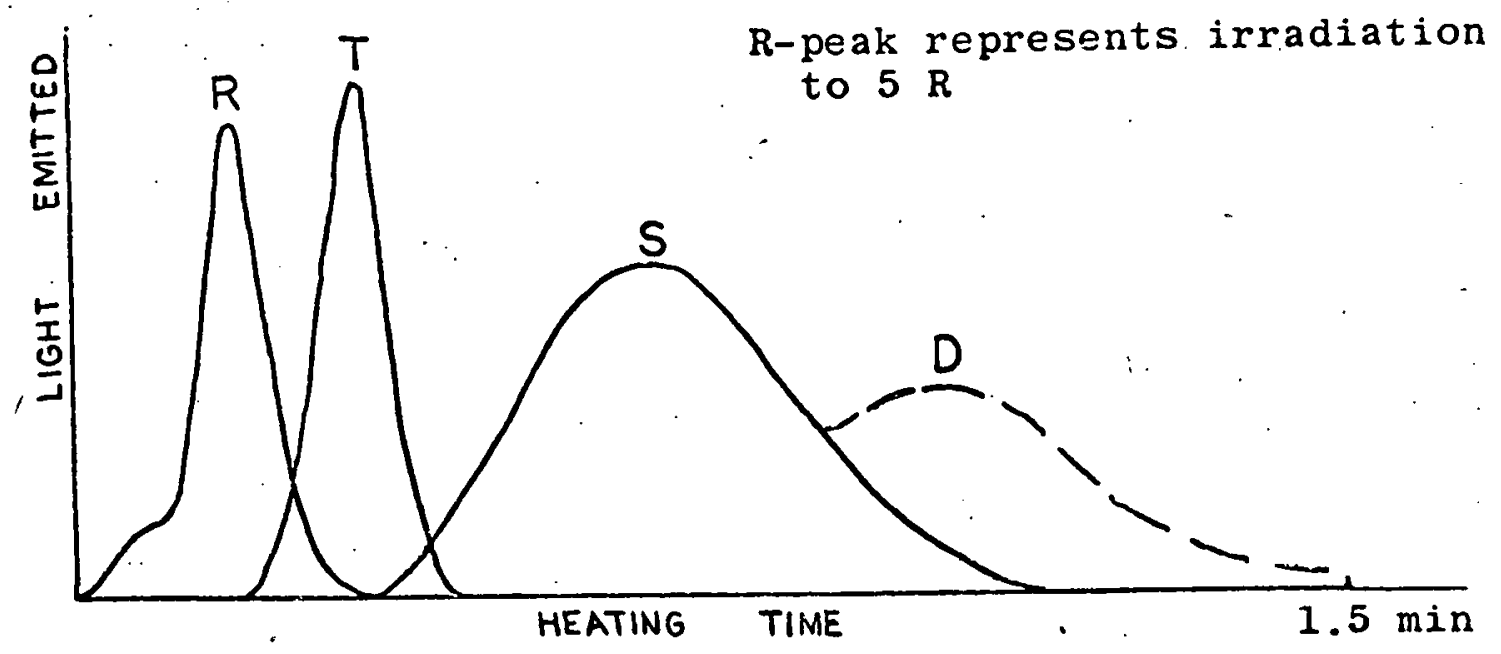

Fig. 1 Glow curves for LiF (H63A) showing the various components of the glow curve.

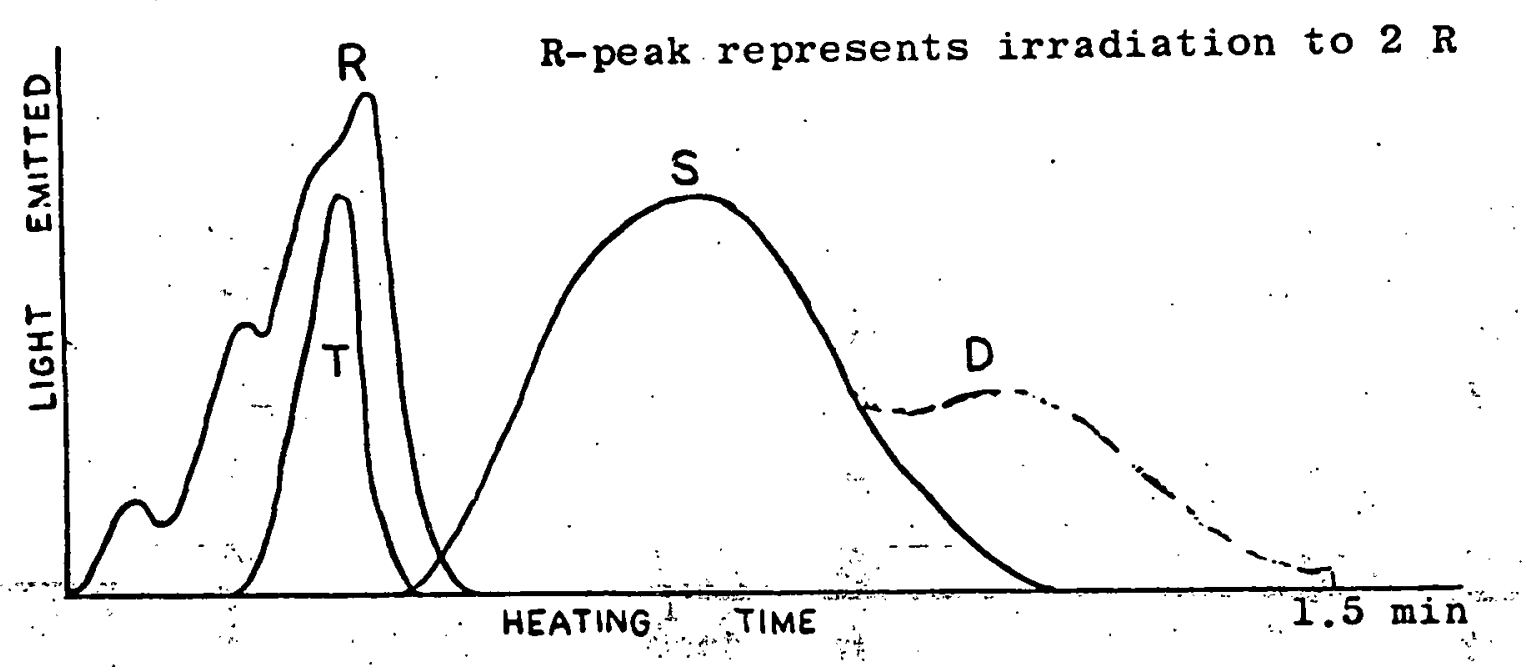

Fig. 2 Glow curves for LiF (TID-100) showing the various comporents of the glow curve.

In both materials the $\mathrm{T}$-peak appeared at approximately $140^{\circ} \mathrm{C}$ and the S-peak at approximately. $315^{\circ} \mathrm{C}$. An infrared filter (Corning 5-61) was used to absorb the contribution of blackbody radiation. If single crystals are used for the 
measurements, the $\mathrm{T}$-peak does not appear and the $\mathrm{S}$-peak 18 reduced by a factor of about 30 .

$$
\text { II. T-PEAK }
$$

The T-peak is the grinding-induced or tribo-thermoluminescence peak. In every case in which the $\mathrm{T}$-peak was induced, the S-peak was also present. When a virgin crystal was ground, sifted, and the thermoluminescence read without any radiation, the $T-, S-$, and $D$-peaks were usually present. The magnitude of the $T$-peak was approximately equivalent to that of the R-peak after 1 to $2 R$. The magnitude of the $S-$ peak under the same conditions was equivalent to an R-peak of about $30 \mathrm{R}$. Under these situations the $\mathrm{D}$-peak was usually less than the $\mathrm{S}$-peak in magnitude. Under normal handling of the powder the T-peak will not reappear. Further grinding or severe shaking of the powder in a metal sieve will generally cause the $T$-peak to reappear but with a reduced magnitude. It should be noted that in TLD-100 the T-peak occurs at nearly the same location as the R-peak and might not be observed for that reason.

\section{S-PEAK}

By shaking the powdered sample of LiF on a sheet of paper or by dumping the sample out of the heating pan and back in again; only the S-peak would appear in the iglow curve. In the H63A material the area of the S-peak was approximateIy equal to the R-peak after. 20-30 R. In TLD-100 the area: was approximately equivalent to 2R. The S-peak also appears after the powder has beentallowed to stand a number of hours. Anattempt was made to graph the growth of this peak as a function of time at room temperature. The powder was left: 
in the original heating pan for various length of time, but the reproducibility was very poor. It was noted, however, that when the samples were kept in an oven of $150^{\circ} \mathrm{C}$ the results reproduced much better. A plot of the total area of the NRI-TL as a function of time at $150^{\circ} \mathrm{C}$ is shown in Fig. 3. Most of this area is due to the $S$-peak.

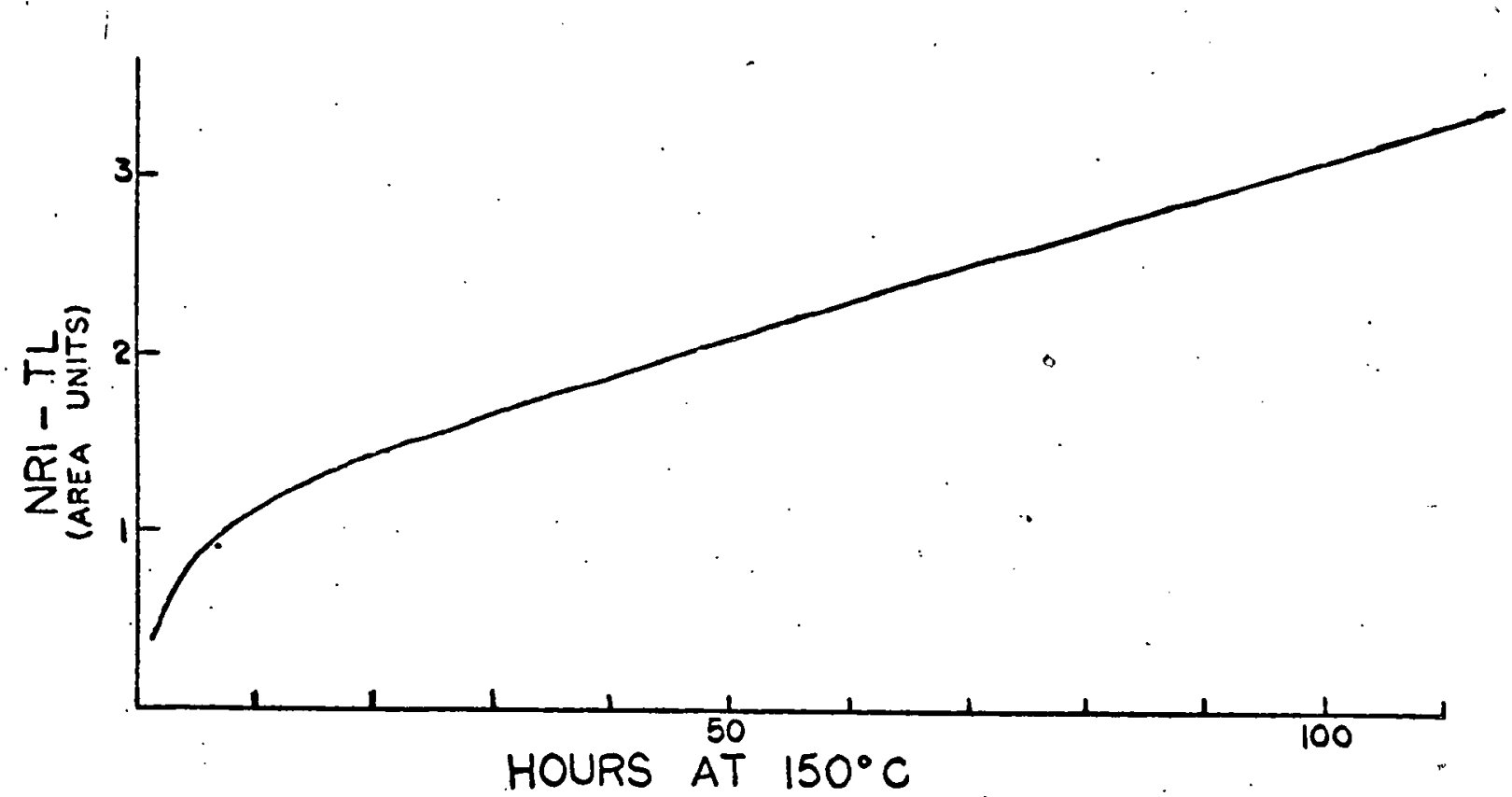

Fig. 3 Growth of the NRI-TL as a function of time at $150^{\circ} \mathrm{C}$.

The S-peak was not induced by radiation but all exposure doseș were $100 \mathrm{R}$ or less.

The $S$-peak was surpressed by using $N_{2}$ gas during the heating cycle.

$\therefore$ Since the S-peak could bestimulated by shaking the sample, it was postulated that the cause was related to the staticalectric charge acquired by the crystals during shakigg. A Shonka electronmeter was used to measure this charge : H63A.

powder was Shaken on paper and then sumped into a pan connected tosthe fiber of the electrometer. A sample of approximately 
$60 \mathrm{mg}$ acquired a positive charge of about $3 \times 10^{-11}$

coulombs. This is equivalent to the sample losing approximately $10^{8}$ electrons. In a separate experiment the powder was placed in a pain biased with \pm 300 volts while it was exposed to $x$-rays to determine if this would tend to increase or decrease the S-peak; no effect was observed. Powder was also shaken on a biased Al plate $(300 \mathrm{v})$. The polarity of the bias was reversed and the results compared. There was no significant change in the S-peak.

$$
\text { IV. D-PE } \Lambda \mathrm{K}
$$

If a sample of LiF powder is allowed to stand for several days or Ionger, the D-peak appears. For periods of about 1 month or less the size of the D-peak was usually less than that of the duration-induced $S$-peak. Because of the $t$ ime involved in studying this phenomenon, no detailed data was obtained.

\section{VACUUM-INDUCED THERMOLUMINESCENCE}

When samples of $\mathrm{H} 63 \mathrm{~A}$ powder were evacuated to about .01 Torr and then returned to atmospheric pressure at various. points of time, it was found to have a pronounced S-peak. The size of the peak was not reproducible but there was a rough correlation with the time the sample was under vacuum. No $D$-peak occurred under these conditions and no relationship. between the $S-p e a k$ and the grain size was observed. 
- CONCLUUSIONS

Nonradiation-induced thermoluminescence has the following characteristics:

1. Reproducibility is poor.

2. It appears to be related to the surface area of the crystals.

3. It is surpresaed in the presence of certain gases.

In agreement with Attix (1) we found a correlation

with the electric charge on the crystals and the S-peak.

In our case we found the same polarity in each test whereas

Attix found varying polarity. It appears likely that the

D-peak is due to the absorption of gases on the crystal

surface. Our results generally confirm those of Attix (1) and Fow ler ${ }^{(2)}$.

\section{REFERENCES}

1. Spurious Signals From TL Dosimeters: A.E. Nash, F.H. Attix, and J.H. Schulman; Naval Research Laboratory
Progress. Report, July 1964 .

2. "Tribo" or Surface Effects as Spurious Thermoluminescent Signals in LiF: J.R. Fowler and $\vec{V}$. Svarcer; International Conference on Luminescent Dosimetry Stanford University,
June 21-23, 1965 (to be published by USAEC). 